http://dx.doi.org/10.30681/23588403v11i01162177

\title{
A SEDUÇÃO DA LINGUAGEM POÉTICA NO ROMANCE “A MENINA QUE ROUBAVA LIVROS"
}

Data de recebimento: $15 / 09 / 2017$

Aceite: 12/11/2017

\author{
Andréa Cristina de PAULA (IFTM) ${ }^{1}$ \\ Luana Aparecida Silva BORGES (IFTM) ${ }^{2}$
}

\begin{abstract}
Resumo: Este artigo visa analisar a presença da função poética da linguagem em A menina que roubava livros, publicado em 2006, que é, atualmente, uma das obras mais vendidas e lidas no Brasil e no mundo. Lendo a obra literária, em questão, percebeu-se a preocupação do narrador não só com o conteúdo da mensagem a ser transmitida ao leitor, mas também com a organização desta (forma), a fim de se alcançarem diferentes efeitos de sentido. Verificou-se, por conseguinte, que a função poética se fazia presente na obra, surgindo, então, a hipótese que norteou o desenvolvimento desta pesquisa, ou seja, a de que tal função deixa a mensagem mais atraente, aumentando o grau de sedução do texto. Esta investigação apoiou-se, basicamente, em pesquisa bibliográfica desenvolvida sob uma abordagem qualitativa, cujo desenvolvimento buscou analisar a presença de recursos poéticos no romance citado e seus efeitos de sentido. Por meio do resultado dessa discussão, chegou-se à conclusão de que a função poética, enriquecida por diferentes recursos estilísticos, contribuiu significativamente para ampliar as possibilidades semânticas do texto, resultando em uma leitura mais agradável e, consequentemente, mais interessante para aquele que lê tal escritura, mantendo A Menina que Roubava Livros na lista dos livros mais lidos no Brasil e no mundo.
\end{abstract}

Palavras-chave: A menina que roubava livros. Função poética. Recepção. Sedução

\begin{abstract}
This article aims to analyze the presence of the poetic function of language in $A$ menina que roubava livros, published in 2006, which is currently one of the most sold and read works in Brazil and the world. Reading the literary work, in question, the narrator's concern was perceived not only with the content of the message to be transmitted to the reader, but also with the organization of this (form), in order to achieve different effects of meaning. It was verified, therefore, that the poetic function was present in the work, thus, the hypothesis that guided the development of this research, that is, that such a function leaves the message more attractive, increasing the seduction degree of the text. This research was based basically on bibliographical research developed under a qualitative approach, whose development sought to analyze the presence of poetic resources in the cited novel and its effects of meaning. Through the result of this discussion, the conclusion was reached that the poetic function, enriched by different stylistic resources, contributed significantly to broadening the semantic possibilities of the text, resulting in a more pleasant and therefore more interesting reading for the one who reads such scripture, keeping A menina que roubava livros in the list of most read books in Brazil and in the world.
\end{abstract}

Keywords: A menina que roubava livros. Poetic function. Reception. Seduction

\footnotetext{
${ }^{1}$ Doutoranda em Estudos Literários pela Universidade Federal de Uberlândia. Docente no Instituto Federal do Triângulo Mineiro, câmpus Patos de Minas, MG, Brasil. E-mail: paulacristinanadrea@gmail.com

${ }^{2}$ Estudante de Iniciação Científica no Instituto Federal do Triângulo Mineiro, câmpus Patos de Minas, MG, Brasil. E-mail: luanaap56@hotmail.com
} 


\section{Revista de Estudos Acadêmicos de Letras}

\section{INTRODUÇÃO}

O romance "A menina que roubava livros", publicado em 2006, e que inspirou a realização do filme homônimo da obra, em 2014, ainda é hoje uma das obras da literatura estrangeira mais vendidas no Brasil. Resumidamente, a história que tanto tem encantado os brasileiros é a de Liesel Meminger, uma menina que vai colecionando livros roubados durante a $2^{a}$ Guerra Mundial, na Alemanha.

Trata-se de uma ficção narrada, inusitadamente, pela Morte, levando o leitor a refletir sobre os acontecimentos desse período histórico, fazendo uso de uma linguagem de fácil compreensão, enfatizando as polêmicas relacionadas à época, como o fanatismo nazista, a perseguição aos judeus e a ditadura de Führer.

Certamente, o sofrimento e o drama vivenciados pela protagonista foram essenciais para atrair a atenção dos leitores. Entretanto, acredita-se que não só o enredo que narra a luta de uma menina judia pela sobrevivência em plena $2^{\text {a }}$ Guerra Mundial tenha ganhado a simpatia do público, mas, acima de tudo, o "como" toda a trama lhe é direcionada.

Quando se lê a narrativa de Markus Suzak, percebe-se a preocupação do narrador não só com a mensagem (conteúdo) a ser transmitida ao leitor, mas também com a organização dessa mensagem (forma), a fim de se alcançarem diferentes efeitos de sentido.

A hipótese que norteou o desenvolvimento desta pesquisa partiu da premissa de que um dos motivos para que o romance A menina que roubava livros tenha obtido tanto sucesso de vendas surge do resultado da organização da mensagem de forma poética. Assim, acreditouse que o diferencial da obra em estudo estivesse na atenciosa escolha e combinação das palavras de forma a "fisgar" a atenção do leitor não só para a mensagem em si (enfatizando o poder transformador da leitura), mas também pela maneira como ela lhe é apresentada (mostrando ao leitor, na prática, como isso acontece).

Verificou-se que o narrador lança mão da metalinguagem, uma das seis funções da linguagem teorizadas por Jakobson (1957), no momento em que, ainda que indiretamente, utiliza-se da palavra imbuída de poesia para demonstrar a sua força propulsora para o crescimento humano. Assim, as palavras tomam a forma da narrativa que apresenta Liesel, que roubava livros para preencher, também com palavras, o vazio de sua solidão, fruto da morte de seu irmão e da ausência da mãe biológica, além de encontrar no universo da leitura combustível para enfrentar as humilhações e intolerâncias nazistas. 
Entretanto, a função da linguagem que atraiu o foco desta investigação e que também pode ser encontrada no romance é a função poética, uma vez que, como já foi exposto, há, além da preocupação com o conteúdo da mensagem, o interesse em deixá-la mais envolvente e agradável aos olhos do leitor.

Segundo Jakobson (1957), a função poética é aquela que põe em evidência a forma da mensagem, ou seja, que se preocupa mais com o como dizer do que com o que dizer. Ou seja, é quando o emissor procura fugir das formas habituais de expressão, buscando surpreender, fugir da lógica ou provocar um efeito humorístico.

Dizendo de outro modo, a função poética da linguagem está presente nos textos, cuja organização é o próprio centro de interesse da comunicação. Nesses casos, na elaboração da mensagem utilizam-se recursos de forma e de conteúdo que chamam a atenção do destinatário para a própria mensagem, causando-lhe surpresa, além de "estranhamento" e prazer estético. Essa mistura de sensações brota da percepção de que a linguagem foge ao convencional e se impõe por um arranjo original de formas e significados.

Essa função se manifesta a partir de um trabalho de escolha das palavras e através da seleção e da combinação cuidadosa das mesmas, o que cria efeitos sonoros e rítmicos no plano formal e efeitos surpreendentes no plano da significação. Privilegia-se, desta maneira, o sentido conotativo das palavras (o chamado sentido "figurado"), passível de diferentes interpretações. A organização do código nas mensagens poéticas coloca as próprias palavras em primeiro lugar, tornando-as, em muitos casos, um fim em si mesmas e não mais um meio de significar outras coisas, embora haja inúmeros casos em que o produtor do texto tenta preencher as duas funções.

O interesse desta pesquisa restringe-se, pois, ao estudo da função poética na obra $A$ menina que roubava livros, com a proposta de analisar que recursos estilísticos contribuem para tornar mais elaborada esta função e, mais especificamente, se tais efeitos aumentam o grau de sedução do texto, a ponto de torná-lo uma das obras de ficção mais vendidas em todo o país.

\section{MATERIAL E MÉTODOS}

Esta investigação apoiou-se, basicamente, em pesquisa bibliográfica desenvolvida sob uma abordagem qualitativa, cujo desenvolvimento buscou analisar a presença de recursos poéticos na obra A menina que roubava livros e seus efeitos de sentido, e, com base na apreciação desses efeitos primeiros, interpretar os seus efeitos segundos - estes, mais "reais", porque ligados aos objetivos do produtor do texto: a sedução do leitor. 
Inicialmente, buscou-se em Jakobson (1957) amparo teórico acerca da comunicação verbal, cuja linguagem, de acordo com o estruturalista, deve ser estudada em toda a variedade de suas funções. Segundo esse estudioso, para toda comunidade linguística, para toda pessoa que fala, existe um sistema de língua, e esse código global representa um sistema de subcódigos relacionados entre si. Sendo assim, toda língua encerra diversos tipos simultâneos, cada um dos quais é caracterizado por uma função diferente.

O autor começa por estabelecer os seis fatores constitutivos e inalienáveis de toda comunicação: o emissor, aquele que fala ou escreve; o destinatário, o receptor da mensagem; o referente, aquilo que se comunica; o contato, físico ou psíquico, entre os interlocutores; o código, por exemplo, a língua que os interlocutores compartilham, a fim de que a mensagem seja recebida; e a própria mensagem, enquanto realidade verbal. A estes seis fatores se referem respectivamente seis funções linguísticas que, raramente, se encontram em estado puro, mas se hierarquizam diversamente, de acordo com as diferentes mensagens: função emotiva ou expressiva, função conativa ou apelativa, função referencial, função fática, função metalinguística e função poética.

Jakobson (1957), na tentativa de explicar a realização da função poética, formulou o seguinte princípio: a função poética projeta o princípio da equivalência do eixo da seleção sobre o eixo da combinação. Para exemplificar esse princípio, o pesquisador entra na estruturação da frase e do texto, lembrando os dois modos fundamentais do comportamento verbal: a seleção (eixo paradigmático) e a combinação (eixo sintagmático).

Com base na teoria de Jakobson (1957), pode-se afirmar que, ao elaborar uma mensagem, o emissor deverá se manter atento às possibilidades de escolha que a língua oferece e saber "jogar" com essas possibilidades, selecionando palavras e combinando-as no contexto de acordo com a finalidade comunicativa do emissor. Se o intuito é construir uma mensagem de cunho objetivo, referencial, por exemplo, o emissor deverá fazer escolhas de acordo com o léxico da língua e combiná-las na frase, mantendo o seu sentido referencial. Se, entretanto, o emissor deseja construir uma mensagem poética, ele deverá saber selecionar palavras, levando em consideração a expressividade de cada uma delas, observando a sua forma e o seu conteúdo para que, combinadas umas às outras no contexto, resulte numa mensagem que prima pela criatividade.

Tomou-se o termo "jogar" emprestado da teoria de Yaguello (1997, pp. 31-32), que considera a língua "um jogo (uma estrutura) cujas regras são falseáveis e que autoriza todos os golpes contestáveis, sem que seja sequer possível delimitar, com precisão, o conjunto de golpes 
permitidos e aqueles que o não são". Comentar-se-á esse jogo teorizado pela autora relacionando-o com o princípio que Jakobson (1957) formulou para explicar a realização da função poética. Segundo Yaguello (1997), embora a linguagem esteja vinculada a regras, é possível tomar algumas liberdades sobre ela. O cerne da criação de uma obra poética estaria, portanto, vinculado a essa liberdade de expressão que o emissor possui de contribuir com o seu toque criador, ao elaborar uma mensagem de cunho poético. E, aplicando sua teoria ao princípio formulado por Jakobson, pode-se dizer que a garantia de um "jogo" perfeito estaria numa consciente escolha lexical (escolha do termo mais adequado) e numa perfeita combinação desses termos (uso da linguagem de forma mais expressiva possível).

Ainda em sua teoria sobre a função poética, Yaguello (1997, p. 32) especifica dois tipos fundamentais de jogo: "o jogo sobre a forma (oral ou escrita), jogo sobre o sentido, e também, naturalmente, jogo sobre os dois ao mesmo tempo (...)" e especifica esses jogos da seguinte maneira:

Os jogos com o som são, essencialmente, a rima, a repetição, a aliteração (repetição de consoantes) a assonância (repetição de vogais), a aproximação de parônimos (palavras foneticamente muito próximas), as pausas falsas, o trocadilho (substituição de sons). Os jogos com o sentido são a inesperada aproximação de palavras estranhas uma à outra, a hábil exploração da sinonímia, da ambiguidade sob todas as suas formas, as violações de sentido propriamente ditas (...), o desvio, a alusão, etc.

Ao “jogar" com a linguagem, portanto, a tessitura sonora dos vocábulos, dos sintagmas e dos enunciados, os efeitos rítmicos e as suas sugestões musicais são valorizados. Aqui, incluise também a fisicalidade dos significantes, que pode avultar também no plano da visualidade (esta função dos significantes só pode ocorrer, como é óbvio, nos textos escritos), no qual a linguagem desenha aquilo que a mensagem transmite. Destacam-se os grafemas, quer considerados isoladamente, quer considerados nas suas combinações mais ou menos extensas, quer considerados nas suas combinações com a mancha tipográfica e com os espaços em branco da página. Podem ocorrer, também, violação e transgressão intencional da norma padrão, uma vez que há a criação de uma linguagem nova, mas vale lembrar que a ruptura será da norma, não do código.

O efeito buscado ao "jogar" com a forma e com o sentido é deixar a mensagem mais elaborada, capaz de provocar um efeito de estranhamento (espanto) no destinatário. E, para que 


\section{Revista de Estudos Acadêmicos de Letras}

esse efeito seja alcançado, a mensagem deverá ser manipulada de forma inovadora e imprevista, capaz de despertar no leitor surpresa e prazer estético.

Pode-se dizer, de forma geral, que a função poética consiste na atualização das potencialidades estruturais da língua. E, por ser centrada na mensagem (cf. JAKOBSON, 1957), estabelece relação consigo mesma. Isso quer dizer que as características físicas do signo (som e visualização) são valorizadas e o sentido que daí advém não é previsto numa mensagem convencional, utilizada nas relações diárias. Em suma, tem-se a manifestação da função poética quando o significante é tão importante quanto o significado, o conteúdo da mensagem é inseparável de sua forma.

De forma sucinta, listar-se-ão as características principais da função poética: busca da expressão mais adequada e mais expressiva possível; linguagem cuidada e selecionada; organiza-se metaforicamente e, portanto, é essencialmente, conotativa e, por isso, "tende a quebrar, pela combinatória de sentidos, velhos e surrados significados" (cf. CHALLUB, 1987); a mensagem é elaborada de forma inovadora e imprevista; utiliza-se combinações sonoras ou rítmicas, jogos de imagens ou se ideias; a linguagem é manipulada de forma pouco convencional; utiliza-se de recursos estilísticos a fim de deixar a mensagem com o maior grau de originalidade possível; sua finalidade é comparar, evocar, sugerir tudo que possa alimentar a imaginação do leitor.

Pode-se encontrar a função poética em poemas, nos quais essa função é predominante; na prosa, que constitui o corpus deste trabalho; e em outras manifestações verbais, como em provérbios: "Quem conta um conto aumenta um ponto" (no qual a função se manifesta através do paralelismo, da rima, da paronímia, da aliteração do fonema /t/ e da assonância do fonema /o/; em título de livros: "Alice no país da linguagem" (cuja função se manifesta através da troca de um termo por outro, o que quebra as expectativas do leitor); em fórmulas bíblicas: "Sede prudentes como as serpentes e simples como as pombas" (cuja função de manifesta através dos recursos do paralelismo, da comparação e da aliteração dos fonemas /s/, /p/); em trava-línguas: "O rato roeu a roupa do rei de Roma" (cuja função se manifesta através dos recursos da assonância do fonema /o/ e da aliteração do fonema /r/; em nomes de filmes: "Deby e Loid" (cuja função poética se manifesta através do recurso à palavra-montagem) etc. Todas essas manifestações da função poética confirmam a citação de Yaguello (1997, p. 33), quando assegura: 


\section{Revista de Estudos Acadêmicos de Letras}

A função poética não é exclusiva da poesia, pelo contrário, engloba todas as produções verbais, espontâneas ou rebuscadas, fixadas numa tradição ou efêmeras, desde que nelas se descubra uma disposição do som e do sentido destinada a chamar a atenção sobre a forma da mensagem, sejam quais forem o seu conteúdo e finalidade comunicativa.

Exemplos de utilização da função poética na prosa são apresentados por Challub (1987, pp. 33-34), que assegura: “Quando a prosa espelha desenhos poéticos no seu sintagma, ela está mais próxima da poesia, uma vez que incorpora procedimentos poéticos”. E Yaguello (1997, p. 31), que considera a língua um “jogo (uma estrutura) cujas regras são falseáveis" e que liga esse aspecto lúdico ou poético ao princípio do prazer, afirma:

O jogo com as palavras, sonoridades e sentido, toda a actividade lúdica e poética que use a linguagem como objecto e meio de expressão constitui uma sobrevivência do princípio do prazer, da manutenção da gratuidade contra o utilitarismo (p. 31)

Dessa maneira, considerando-se que todo ato de fala tem um componente perlocutório, entendendo-se "ato perlocutório" por "aquele destinado a exercer efeitos sobre o interlocutor" (cf. KOCH, 1996, p. 20), este aspecto perlocucionário manifesta-se de forma acentuada na narrativa analisada, organizando a mensagem de maneira agradável, no intuito de seduzir o leitor.

Nesse viés, o referencial teórico apresentado delineia a postura metodológicoqualitativa que se seguiu para a concretização desta pesquisa, ou seja, dentro das tendências de estudos atuais, em que se busca o "ponto de encontro" de diferentes linguagens, analisaram-se os recursos da função poética como instrumento de sedução na narrativa A menina que roubava livros.

Além de leitura bibliográfica acerca da função poética da linguagem, conforme proposta de Jakobson (1957) e demais estudiosos que se debruçaram sobre o tema, leu-se o livro que constitui o corpus deste trabalho, detectando, numa primeira leitura, a evidência da utilização de algum tipo de recurso estilístico característico da função poética. Em seguida, analisou-se e categorizou-se a utilização dos recursos poéticos e seus efeitos de sentido na obra, avaliando o grau de recorrência dos mesmos no romance e refletindo se tais recursos a serviço da função poética contribuíram de forma significativa para conquistar a empatia do público 
leitor. Ademais, com o propósito de complementar as observações obtidas com a pesquisa, aplicou-se um formulário a informantes, constituídos por 27 estudantes do ensino médio de uma escola pública federal. Tal formulário - contendo 7 excertos extraídos do romance em foco com o recurso da função poética e os mesmos excertos sem o referido recurso - objetivou verificar se os informantes preferem textos em que se utilizam a função poética ou não. Todos os resultados obtidos por meio dessa investigação científica podem ser identificados na seção a seguir.

\section{RESULTADOS E DISCUSSÕES}

O desenvolvimento deste estudo possibilitou a confirmação da hipótese inicial que norteou este trabalho, ou seja, a de que a função poética da linguagem foi utilizada, de forma estratégica, na obra $A$ menina que roubava livros, de modo a deixar a mensagem do texto mais atrativa para o leitor. Tal função da linguagem, no sentido a que lhe atribui Jakobson (1957), foi utilizada na obra para que esta se configure em prosa poética, cuja função, mais que narrar uma história, preenche-a com elementos próprios da poesia (cf. CHALLUB, 1987). Com o intuito de registrar uma história em formato literário, Markus Zuzak faz uso da função poética que, como assegura Jakobson (1957), é a função que não se preocupa apenas com o que se diz, mas também com o "como" se diz, extrapolando a normalidade expressiva habitual, com a premissa de deixar o texto mais atraente, surpreendente, fugindo da lógica ou até mesmo provocando humor.

O escritor soube escolher suas palavras de modo a tecê-las, criando um cobertor bordado cuidadosamente de significados e sentidos, e, nesse jogo das possibilidades linguísticas (cf. YAGUELLO, 1997), ganha relevo na obra em questão o sentido conotativo das palavras, ampliando as possibilidades de interpretação do texto. E, para atingir tal feito, o autor valeu-se de vários recursos estilísticos (que enriqueceram a estética e o conteúdo da mensagem).

Na obra de quase quinhentas (500) páginas, o autor não economiza na utilização dos recursos estilísticos ao narrar os acontecimentos do Holocausto durante a Segunda Grande Guerra Mundial na Alemanha. Resumidamente, o livro narra a história de Liesel, que vê sua vida mudar completamente quando parte com sua mãe e irmão para seu novo lar e, no caminho, presencia a morte de seu irmão mais novo. Aliás, é no enterro do irmão que a mesma inicia a sua sina: roubar livros e esquivar-se do célebre narrador da obra, a Morte. Após a perda fraterna, 


\section{Revista de Estudos Acadêmicos de Letras}

a jovem garota é mandada para a casa da família Hubermann, lugar onde enfrenta grandes desafios, prova o gosto do amor, amizade e vive novamente a experiência de se perder alguém que ama.

A menina inicia então uma leva de roubos, fato que justifica o título do romance, no qual a história, de caráter dramático e de contexto histórico angustiante, é narrada de forma irônica e até engraçada. Para tanto, como já se afirmou, tal narrativa se apoiou nos recursos estilísticos mencionados anteriormente, num processo que atrela as figuras de linguagem à intencionalidade do texto, ou seja, tornar a mensagem escrita agradável aos leitores.

Analisando a obra, verificou-se que os recursos poéticos mais recorrentes na obra em questão foram: comparação, metáfora, ironia, personificação, pleonasmo, eufemismo, antítese, paradoxo, hipérbole e metonímia. Cada um desses elementos foi utilizado para obter um efeito de sentido específico.

A seguir, listar-se-ão algumas passagens da obra em que se pode verificar o trabalho com a seleção e combinação das palavras, privilegiando-se o sentido conotativo da linguagem. Na página 29, por exemplo, quando o narrador descreve Rosa Hubermann, mãe adotiva de Liesel, o narrador utiliza-se de comparações inusitadas, a fim de se enfatizar o mau-humor da personagem: "Rosa Hubermann, que parecia um pequeno guarda-roupa com um casaco jogado por cima (...) era quase engraçadinha, não fosse pelo rosto aborrecido, que lembrava papelão amarrotado". Aqui, a comparação se manifesta ao se aproximar as características de Rosa com as de um guarda-roupa e um papelão amarrotado, criando-se uma imagem de uma mulher com poucas curvas e mal-humorada.

As expressões hiperbólicas também são bastante utilizadas na obra, como, na página 33, quando o narrador, novamente, para enfatizar as reclamações da personagem Rosa Hubermann, comenta: "Não havia nada senão tinta seca, a respiração difícil e o dilúvio de impropérios de Rosa". A hipérbole se manifesta no excerto, então, por meio da expressão “dilúvio de impropérios", construindo uma imagem que exagera a quantidade de queixas da personagem.

Em direção contrária, também o eufemismo é recorrente no romance, como na seguinte passagem: “... entregando almas à estrela rolante da eternidade” (p. 25), excerto que faz referência às atividades da Morte, uma das personagens da história. Ou como na expressão: "Ele deitou em meus braços" (p. 463), isto é, nos braços daquela que narra toda a trama, a Morte; tal trecho faz referência ao falecimento do irmão de Liesel. Ambas as passagens apresentadas suavizam um fato considerado desagradável da vida, que é a morte. 
O pleonasmo estilístico também pode ser encontrado, como na página 34, em que a Morte descreve Hans, pai adotivo de Liesel, e o compara com a protagonista, na seguinte passagem: "A criança humana - tão mais arguta, às vezes, do que o adulto espantosamente grave!". Nessa passagem, o pleonasmo se manifesta por meio da expressão "criança humana"; ora, numa leitura rápida, pode-se interpretar que toda criança é humana, mas no contexto da obra, tal vocábulo é plurissignificativo, uma vez que mais que fazer referência à raça humana, alude ainda à sua natureza (no caso, à natureza perspicaz da personagem Liesel).

Também o paradoxo marca presença na obra em questão. A título de exemplificação, recorre-se aqui à passagem, que pode ser encontrada na página 37, em que Hans busca confortar Liesel diante de seus seguidos pesadelos noturnos: “A confiança se acumulava depressa, graças sebretudo à força bruta da delicadeza do homem" - o paradoxo se expressa aqui pelas ideias contraditórias que se fundem de brutalidade e delicadeza.

Além de todos os recursos já mencionados, a metonímia pode ser verificada na página 48, na passagem em que são narrados desfiles de soldados nazistas pela principal avenida de Molching, cidade onde se passa a história: "Os rostos fixavam-se adiante, concentrados" - no caso, os rostos representam os soldados, em um processo em que a parte simboliza o todo.

A metáfora também pode ser localizada em diferentes pontos do romance, como na página 13, quando o narrador acentua o clima frio da Europa: "As árvores usavam cobertores de gelo" - a expressividade metafórica evidencia-se pela criação da imagem poética da neve cobrindo as árvores, de modo semelhante a um cobertor; há, pois uma aproximação implícita entre a ideia de frio (representada pelas camadas de partículas de gelo) e a ideia de proteção (representada pelo cobertor que, normalmente transmite calor, mas que, no contexto em questão, num processo que também desencadeia o paradoxo das imagens, protege pelo frio).

Há ainda a antítese que consiste na utilização de expressões de significados opostos, um recurso bastante utilizado na obra em questão, como na passagem que chama a atenção para os sentimentos opostos que Liesel tinha por Max: "Amava e odiava seu melhor amigo" (p. 77).

Não se pode deixar de destacar o humor irônico da Morte, um dos recursos mais recorrentes na obra em estudo, como na passagem sarcástica em que a Morte anuncia o início

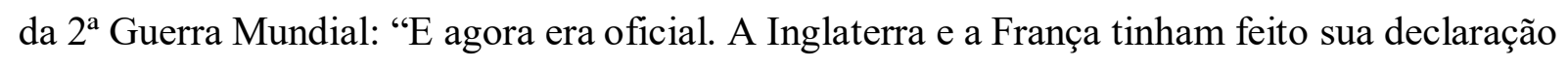
à Alemanha. Para roubar uma frase de Han Hubermann, vai começar a diversão" (p. 68). Ora, que diversão é essa que se inicia com a guerra?

Organizando estes recursos, criou-se uma tabela (que está disponível no anexo 1), a fim de apresentar, de forma categórica, o resultado obtido com esta pesquisa. Quanto à pesquisa 
realizada junto aos 27 informantes, a fim de aferir a preferência dos mesmos sobre a presença ou não da função poética na obra $A$ menina que roubava livros, elaborou-se questionário, contendo trechos poéticos extraídos do romance, os quais foram apresentados aleatoriamente aos informantes, numa disposição no papel que permitiu ao estudante assinalar com um "X", de acordo coma sua preferência, o enunciado "com recurso" ou "sem recurso".

Considerando-se que um total de 27 pessoas responderam ao formulário de pesquisa, contendo 7 enunciados diferentes e que o questionário permite ao leitor marcar uma resposta para cada excerto, isso resulta em 189 respostas, dentre as quais constatou-se que, dos 27 informantes, $57 \%$ demonstraram preferir o texto com o recurso poético, ao passo que $43 \%$ votaram em enunciados sem o recurso, conforme disposição gráfica abaixo:

\section{PREFERÊNCIA QUANTO À UTILIZAÇÃO DE FIGURAS DE LINGUAGEM}

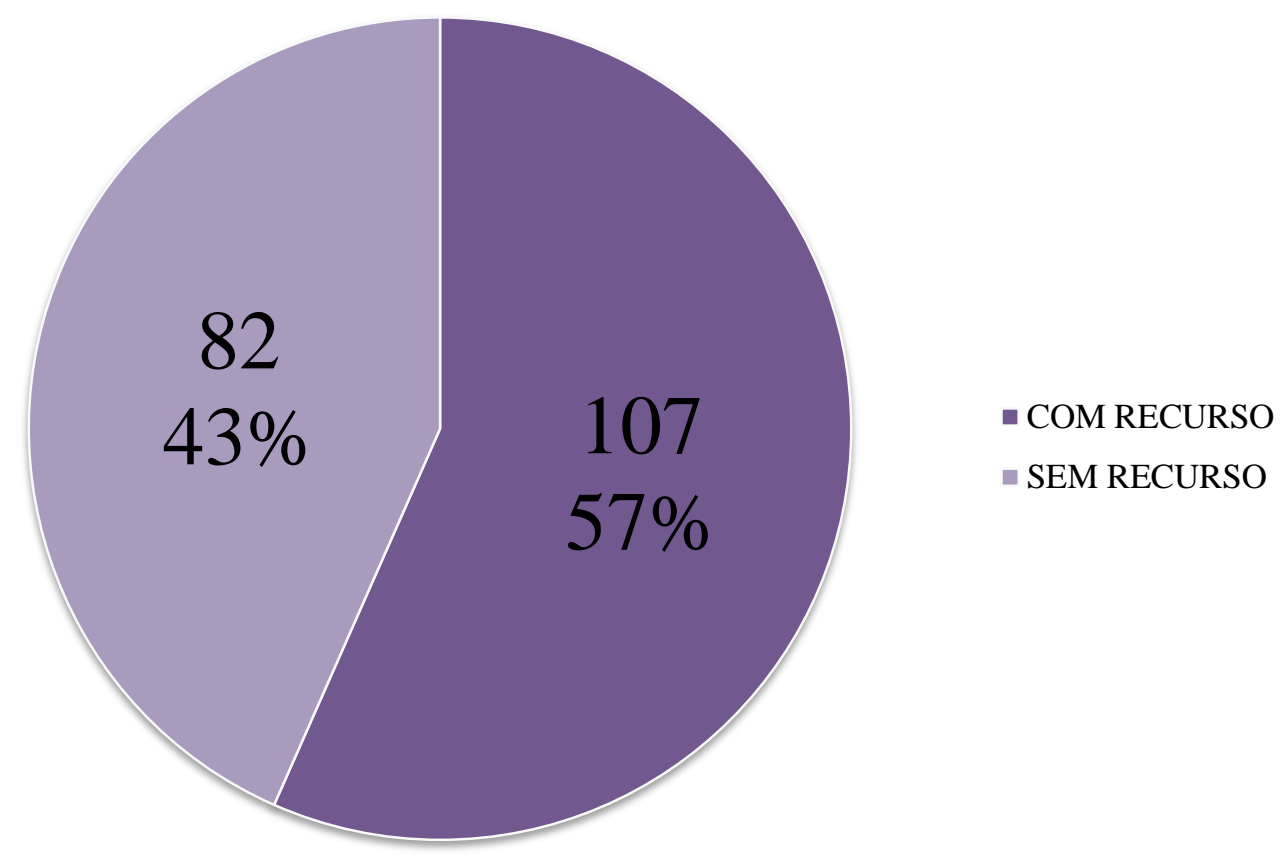

\section{CONSIDERAÇÕES FINAIS}




\section{Revista de Estudos Acadêmicos de Letras}

Diante dos dados presentados, percebe-se que o uso destes recursos é um dos fatores responsáveis por tornar o livro um best-seller tão procurado pelo público leitor. Nesse sentido, mesmo abordando o complexo tema histórico da Segunda Guerra Mundial, o romance consegue prender a atenção do leitor e fazer com que este viva a história de uma forma diferente da que se é estudada no ambiente escolar, visualizando tal cenário guerrilheiro do ponto de vista da Morte e ainda do ponto de vista de Liesel, a principal personagem protagonista da narrativa.

Tais recursos propiciam a quem lê compreender a experiência pela qual passou Liesel: sua tristeza ao perder as pessoas que ama e que aprendeu a amar; seu contentamento, ao possuir as coisas mais simples, como a companhia do pai; suas gargalhadas ao ouvir os impropérios de Rosa; sua emoção e amizade para com Max; sua insegurança e confusão em relação aos seus sentimentos, seus medos, seus desejos etc.

A Morte sendo o narrador da história desencadeia outro fator que levou o livro ao sucesso. Mesmo possuindo um julgamento negativo dos homens, abrilhanta ainda mais a narrativa com suas falas repletas de ironia, atraindo a atenção dos leitores. Tal recurso parece ter sido agregado exclusivamente às passagens ecoadas pela voz da Morte. Em basicamente todas as participações, há um tom irônico, seja direcionado à guerra, ao fanatismo, aos alemães ou até mesmo ao seu próprio "trabalho". A figura do narrador ainda provoca no leitor inúmeras curiosidades, como de saber o porquê de se escolher a Morte para se narrar uma história.

Portanto, observa-se o constante uso das figuras de linguagem na obra, o que desencadeou o desenvolvimento desta pesquisa, a começar pela personificação da Morte (recurso que encabeça a gama dos elementos mais encontrados na obra), como se pôde perceber pelos dados apresentados. Alguns mais presentes que outros, como é o caso da prosopopeia, a comparação e a metáfora, que se mostraram mais recorrentes que os demais, sendo o pleonasmo e o eufemismo as figuras de linguagem utilizadas com menor frequência. De qualquer forma, talvez por se tratar de um texto em prosa, os recursos que "jogam" mais com a ideia (com a finalidade de ampliar o significado do texto) foram mais explorados, em relação aos recursos que utilizam os jogos com a "forma" (cf. YAGUELLO, 1997).

Buscou-se refletir sobre a ocorrência da função poética no romance sob uma perspectiva de Austin (1990), segundo o qual todo ato de fala procura exercer um efeito no interlocutor, em maior ou em menor grau. Tal pesquisa também se utilizou de outros meios de investigação, com a aplicação dos questionários aos informantes, a fim de obter dados mais empíricos e precisos quanto à observação se tais recursos ampliam ou não o grau de recepção da obra. Por meio do resultado dessa discussão, chegou-se à conclusão de que a função poética, 
enriquecida pelas figuras de linguagem apresentadas, contribuiu significativamente para ampliar as possibilidades semânticas do texto, resultando em uma leitura mais agradável e, consequentemente, mais interessante para aquele que lê tal escritura, tornando A Menina que Roubava Livros um aclamado best-seller que, mesmo com o passar dos anos, ainda se mantém na lista dos livros mais lidos no Brasil e no mundo.

\section{REFERÊNCIAS}

AUSTIN, John L. Quando dizer é fazer. - Trad. Danilo Marcondes de Souza

Filho. Porto Alegre: Editora: Artes Médica, 1990.

CHALLUB, Samira. Funções da Linguagem. São Paulo: Ática, 1987.

KOCH, Ingedore G. Villaça. Argumentação e Linguagem. São Paulo: Cortez, 1996.

JAKOBSON, Roman. Linguística e Comunicação. Trad. De Isidoro Blikstein e José Paulo Paes. São Paulo: Cultrix, 1974.

SUZAK, Markus. A menina que roubava livros. Tradução de Vera Ribeiro; ilustrações de Trudy White. Rio de Janeiro: Intrínseca, 2007.

YAGUELLO, Marina. Alice no país da linguagem: Para compreender a linguística. Lisboa: Editorial Estampa, 1997.

\section{Anexo}

\section{Recursos poéticos mais utilizados na obra A Menina que Roubava Livros}

\begin{tabular}{|c|c|c|}
\hline Recursos & Página & Expressão \\
\hline $\begin{array}{l}\text { Metáfora: consiste em empregar } \\
\text { uma palavra em um sentido que } \\
\text { não lhe é comum ou próprio, } \\
\text { sendo esse novo sentido } \\
\text { resultante de uma relação de } \\
\text { semelhança, de interseção entre } \\
\text { dois termos. }\end{array}$ & $\begin{array}{l}25 \\
54 \\
90 \\
372 \\
467 \\
34 \\
55\end{array}$ & $\begin{array}{l}\text { “... entregando almas à estrela rolante da eternidade.” } \\
\text { “... a Lua estava costurada no céu naquela noite." } \\
\text { “... e cozinhava o fluxo acelerado de seu sangue." } \\
\text { “... aguardou a asfixia do sono.” } \\
\text { "Papai era um acordeão.” } \\
\text { "Liesel observou a estranheza dos olhos de seu pai de } \\
\text { criação. Eram feitos de bondade e prata.” } \\
\text { “Pelo menos um tinha que ser a maçã podre”. }\end{array}$ \\
\hline Comparação: consiste em & 24 & “...o espírito do menino estava mole e frio, feito \\
\hline
\end{tabular}




\begin{tabular}{|c|c|c|}
\hline $\begin{array}{l}\text { aproximar dois seres em razão } \\
\text { de alguma semelhança existente } \\
\text { entre eles, de modo que as } \\
\text { características de um sejam } \\
\text { atribuídas ao outro, e sempre por } \\
\text { meio de um elemento expresso: } \\
\text { como, tal, qual, semelhante a, } \\
\text { que nem, etc. }\end{array}$ & $\begin{array}{l}133 \\
313 \\
465\end{array}$ & $\begin{array}{l}\text { sorvete." } \\
\text { "Hans ajeitou o corpo e seus ossos rangeram como as } \\
\text { tábuas invejosas do piso." } \\
\text { "O céu estava pesado e fundo feito areia movediça." } \\
\text { "Tempos difíceis estavam por vir. Como um desfile." } \\
\text { "Frau Holtzapfel estirava-se no chão como uma } \\
\text { tesoura." } \\
\text { "O corpo era alto e pesado como um carvalho. O cabelo } \\
\text { lembrava lascas de madeira". (Pág. 55) } \\
\text { "(...) e ele tinha os cabelos louros espetados e uma pele } \\
\text { feito tinta cor de pérola." } \\
\text { "Era como se o globo inteiro estivesse vestido de neve } \\
\text { (...). As árvores usavam cobertores de gelo" } \\
\text { "Uma neve suja, estendida feito um tapete" }\end{array}$ \\
\hline $\begin{array}{l}\text { Metonímia: substituição de uma } \\
\text { palavra por outra em razão de } \\
\text { haver entre elas uma relação de } \\
\text { interdependência, de inclusão, de } \\
\text { implicação. }\end{array}$ & $\begin{array}{l}67 \\
99 \\
41\end{array}$ & $\begin{array}{l}\text { “As vozes infantis rindo...” (as crianças) } \\
\text { “... morar duas semanas na rua Himmel.” } \\
\text { "Esfregou bem o carvão no corpo, numa camada } \\
\text { espessa, até ficar coberto de preto.” (com a cor preta). } \\
\text { "O mundo discutiu o assunto.” (as pessoas) } \\
\text { “... juventude da Alemanha marchava para a Prefeitura } \\
\text { e a praça...” (os jovens) } \\
\text { "Um roupão de banho atendeu a porta". }\end{array}$ \\
\hline $\begin{array}{l}\text { Antítese: utilização de palavras } \\
\text { que se opõem quanto ao sentido. }\end{array}$ & $\begin{array}{l}37 \\
77 \\
91\end{array}$ & $\begin{array}{l}\text { “... a força bruta da delicadeza..." } \\
\text { “Amava e odiava seu melhor amigo..." } \\
\text { “A escuridão, a luz." }\end{array}$ \\
\hline $\begin{array}{l}\text { Hipérbole: expressão de uma } \\
\text { ideia com exagero. }\end{array}$ & $\begin{array}{l}29 \\
33 \\
37 \\
46 \\
101\end{array}$ & $\begin{array}{l}\text { "Um bando de lágrimas lhe escorria dos olhos...” } \\
\text { “... dilúvio de impropério de Rosa." } \\
\text { “... mar de lençóis." } \\
\text { "Doeu como o diabo." } \\
\text { "Cascatas de palavras." }\end{array}$ \\
\hline $\begin{array}{l}\text { Paradoxo: uso de palavras ou } \\
\text { ideias que, embora opostas } \\
\text { quanto ao sentido, se fundem em } \\
\text { um enunciado. }\end{array}$ & $\begin{array}{l}279 \\
437 \\
310 \\
459\end{array}$ & $\begin{array}{l}\text { "Quanto mais frio ficava, mais derretia." } \\
\text { “" Matou-se por querer viver.” } \\
\text { “... um novo começo, um novo fim.” } \\
\text { “odiei as palavras e as amei." }\end{array}$ \\
\hline \begin{tabular}{|lrr} 
Personificação ou & Prosopopeia: \\
consiste & em & atribuir \\
características & dos & seres
\end{tabular} & $\begin{array}{l}38 \\
64 \\
102\end{array}$ & $\begin{array}{l}\text { “...e a música olhava de frente para Liesel.” } \\
\text { “A cozinha esperou.” } \\
\text { “... e o cheiro de puro suor alemão lutou para se soltar, }\end{array}$ \\
\hline
\end{tabular}




\begin{tabular}{|c|c|c|}
\hline $\begin{array}{l}\text { humanos à seres inanimados ou } \\
\text { irracionais, como sentimento, } \\
\text { linguagem e ações. }\end{array}$ & $\begin{array}{l}163 \\
371 \\
95\end{array}$ & $\begin{array}{l}\text { a princípio, depois, desprendeu-se. Contornou esquina } \\
\text { após esquina, até todos nadarem nele." } \\
\text { "As palavras o seguiram." } \\
\text { "O ar transpirava pelas mangas de seu pijama." } \\
\text { "Não pode ficar ai sentado, esperando que o novo } \\
\text { mundo venha buscá-lo". } \\
\text { Você tem que sair para fazer parte dele...". } \\
\text { "A cama que fora destinada a seu irmão flutuava". } \\
\text { "Cartas Mortas" }\end{array}$ \\
\hline $\begin{array}{l}\text { Ironia: afirmação do contrário } \\
\text { do que se quer dizer ou } \\
\text { expressar. }\end{array}$ & $\begin{array}{l}57 \\
65 \\
142 \\
68 \\
91 \\
118 \\
67 \\
65\end{array}$ & $\begin{array}{l}\text { "Como sempre, eles tinham sido aplaudidos.” (os } \\
\text { alemães) } \\
\text { “... você saberá ler aquele livro horroroso das } \\
\text { sepulturas de olhos fechados.” } \\
\text { “... a Alemanha nazista era um lugar maravilhoso”. } \\
\text { "E agora era oficial. A Inglaterra e a França tinham } \\
\text { feito sua declaração à Alemanha. Para roubar uma frase } \\
\text { de Han Hubermann, vai começar a diversão” } \\
\text { "Liesel Meminger estava pronta. Feliz Aniversário, } \\
\text { Herr Hittler. Muitos anos de vida”. } \\
\text { "Na escuridão de meu coração tenebroso, eu sei. Ele } \\
\text { teria adorado, com certeza. Viu? Até a morte tem } \\
\text { coração". } \\
\text { "A Rua Munique, como todas as outras ruas principais } \\
\text { da Alemanha, ganhou vida com a guerra”. } \\
\text { "Fez um dia frio em Molching quando a guerra } \\
\text { começou e minha carga de trabalho aumentou”. }\end{array}$ \\
\hline $\begin{array}{l}\text { Pleonasmo: repetição de uma } \\
\text { mesma ideia por meio de } \\
\text { vocábulos ou expressões } \\
\text { diferentes. }\end{array}$ & \begin{tabular}{|l|}
34 \\
285
\end{tabular} & $\begin{array}{l}\text { “... A criança humana..." } \\
\text { "O soldado estava enterrado no chão." }\end{array}$ \\
\hline $\begin{array}{l}\text { Eufemismo: Consiste em } \\
\text { empregar uma expressão } \\
\text { mais suave, mais nobre ou } \\
\text { menos agressiva, para } \\
\text { comunicar alguma coisa } \\
\text { áspera, desagradável ou } \\
\text { chocante. }\end{array}$ & 25 & $\begin{array}{l}\text { “... entregando almas à estrela rolante da } \\
\text { eternidade." } \\
\text { "Ele deitou em meus braços e descansou". }\end{array}$ \\
\hline
\end{tabular}

